\title{
HIV-Positive Patients with Liver Metastases from Colorectal Cancer Deserve the Same Therapeutic Approach as the General Population
}

\author{
Massimiliano Berretta ${ }^{a} \quad$ Ernesto Zanet $^{\mathrm{a}}$ Francesco Basile $^{\mathrm{b}} \quad$ Anna L. Ridolfo $^{\mathrm{c}}$ \\ Fabrizio Di Benedetto $^{d} \quad$ Alessandra Bearz $^{\mathrm{a}}$ Salvatore Berretta ${ }^{\mathrm{b}} \quad$ Guglielmo Nasti $^{\mathrm{e}}$ \\ Umberto Tirellia \\ ${ }^{a}$ Division of Medical Oncology A, National Cancer Institute, Aviano, \\ ${ }^{\mathrm{b}}$ Department of Surgery, University of Catania, \\ ' Department of Clinical Sciences, Section of Infectious Diseases and Immunopathology, 'L.Sacco' Hospital, University of Milan, \\ ${ }^{\mathrm{d}}$ Liver and Multivisceral Transplant Centre, University of Modena and Reggio Emilia,

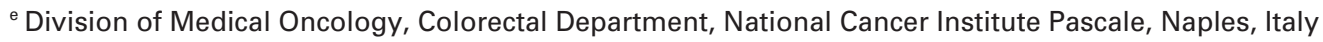

\section{Key Words}

Liver metastases · Colorectal cancer · HIV infection . HAART

\section{Schlüsselwörter}

Lebermetastasen · Kolorektales Karzinom · HIV-Infektion · HAART

Colorectal cancer (CRC) is a leading cause of cancer death in the general population, with approximately 350,000 new cases reported annually in Western countries [1]. Approximately $25 \%$ of patients present liver metastases (LM) at the time of diagnosis, and another $60 \%$ will develop them [2]. In fact, the liver is the most frequent site of disease involvement in metastatic CRC (mCRC). These patients have a poor prognosis, despite improvements in survival with chemotherapy. Resection of LM remains the treatment of choice, even if initially most patients are not eligible for surgery due to unfavorable location, size, or number of metastases, insufficient liver reserve, or extra-hepatic disease. In this setting, systemic chemotherapy is the first option, but survival is poor and only $2-8 \%$ of patients who do not achieve surgical resection are alive at 5 years. In recent years, however, improved diagnostic tools and treatment options have decreased mortality rates [3]. In patients who achieve a complete surgical resection, the 5-year survival rate is approximately $25-35 \%$ [4]. Furthermore, recent data suggest that radical surgery rates and survival rates are improved by pre-operative chemotherapy in both initially resectable and unresectable liver disease [4].
The incidence of CRC is increased in the human immunodeficiency virus (HIV)-positive population, mostly because highly active antiretroviral therapy (HAART) improved survival and prolonged life expectancy [5, 6]; however, data on CRC in patients with HIV infection is limited. From the gastrointestinal tumors database, within the Italian Cooperative Group on AIDS and Tumors (GICAT), we identified 3 out of 14 HIV-positive patients with initially unresectable LM from CRC for whom a multidisciplinary approach (MA) was performed. All 14 patients underwent FOLFOX-4 treatment, but only in 3 of them the surgical approach was possible. Two patients were female and one male, with a median age of 45 years. The risk for HIV infection was: intravenous drug use in 1 patient and heterosexual contact in the other 2 patients. The HIV infection clinical characteristics at cancer diagnosis are shown in the table 1. The ECOG performance status (PS) was 0 . All patients had synchronous LM at diagnosis with 2 and 3 lesions in two and one patient, respectively. All lesions had a diameter of $<5 \mathrm{~cm}$ with bilobar and unilobar liver involvement in 1 and 2 patients, respectively. All patients underwent neoadjuvant chemotherapy: 2 patients with 3 cycles of Folfox-4 [7] which consisted of biweekly oxaliplatin $85 \mathrm{mg} / \mathrm{m}^{2}$ day 1 , followed by leucovorin (LV) $200 \mathrm{mg} / \mathrm{m}^{2}$ and bolus fluorouracil (5-FU) $400 \mathrm{mg} / \mathrm{m}^{2}$ days 1 and 2, and then continuous-infusion 5 -FU $600 \mathrm{mg} / \mathrm{m}^{2}$ over $46 \mathrm{~h}$ days $1-2$, and 1 patient with 6 cycles of Folfiri [8] which consisted of biweekly irinotecan $180 \mathrm{mg} / \mathrm{m}^{2}$ day $1, \mathrm{LV} 400 \mathrm{mg} / \mathrm{m}^{2}$ day 1 , bolus 5 -FU $400 \mathrm{mg} / \mathrm{m}^{2}$ day 1 followed by continuous-infusion 5-FU 2,400 mg/m² over $46 \mathrm{~h}$, before liver surgery. All patients continued HAART during the MA. Before beginning treat-

\section{KARGER}

Fax +497614520714

Information@Karger.de

www.karger.com (c) 2010 S. Karger GmbH, Freiburg

Accessible online at:

www.karger.com/onk 
Table 1. Clinical characteristics of HIV infection at cancer diagnosis

\begin{tabular}{ll}
\hline HIV stage, $\mathrm{n}$ & 3 \\
$\mathrm{~A} 1 \rightarrow \mathrm{A} 3$ & 0 \\
$\mathrm{~B} 1 \rightarrow \mathrm{B} 3$ & 0 \\
$\mathrm{C} 1 \rightarrow \mathrm{C} 3$ & \\
Median CD4+ count, cells/mm $\mathrm{mm}^{3}$ (range) & $315(225-360)$ \\
HIV diagnosis & $390(285-570)$ \\
CRC diagnosis & $345(270-480)$ \\
During AT & \\
HIV RNA, copies/ml (range) & $70(<50-400)$ \\
HIV diagnosis & $<50$ \\
CRC diagnosis & $<50$ \\
During AT & \\
HAART, $\mathrm{n}$ & 2 \\
Lamivudine/zidovudine/efavirenz & 1 \\
Retrovir/epivir/efavirenz &
\end{tabular}

$\mathrm{HIV}=$ Human immunodeficiency virus; $\mathrm{CRC}=$ colorectal cancer;

$\mathrm{AT}=$ antiblastic treatment; HAART $=$ highly active antiretroviral therapy.

ments, patients were staged by means of physical examinations, complete blood cell count (including CD4), blood chemistry, HIV viral load, serum carcinoembryonic antigen analysis, and total body computed tomography scan. The chemotherapy treatments and concomitant HAART were well tolerated with no grade 3-4 (hematological and extrahematological) toxicities or opportunistic infections. In all patients, the HIV infection was well-controlled and the PS remained good during MA. Two partial remissions and a stable disease were obtained with the Folfox-4 and Folfiri regimen, respectively. Two patients underwent liver segmentectomy, and one liver segmentectomy with radio frequency ablation of a controlateral LM. Radical surgery was obtained in all patients. After the liver surgery, 2 patients completed their chemotherapy treatment with 3 further cycles of Folfox-4, and 1 patient started the Folfox-4 regimen. No peri-operative major complications occurred; the pre-operative concomitant use of chemotherapy and HAART did not increase liver toxicity. After a median follow-up of 21 months, 2 patients are disease-free, and in 1 patient lung metastases occurred.

Since we have described only 3 cases, significant conclusions cannot be drawn, but to our knowledge, this is the largest series of mCRC with LM and HIV infection treated with MA described so far. We strongly support the importance of an aggressive approach in HIV-positive patients who are not being offered the same opportunity as HIV-negative patients of an aggressive surgical therapy. In our opinion, these strategies must encompass the following: i) accurate patient selection before MA with regards to control of HIV status, PS, and potentially resectable LM; and ii) a multidisciplinary team, including surgeons, infectious diseases' specialists and medical oncologists, with proven expertise in the management of this particular setting of patients. In conclusion, the aim of this report is to describe, for the first time, the feasibility and efficacy of an aggressive MA in this particular setting, and to suggest, in light of these data, that HIV-positive patients deserve the same therapeutic options as the general population; all physicians must be aware that HIV infection should not be considered a discriminating factor in the therapeutic decision.

\section{Conflict of Interest}

The authors declare no conflict of interest.

\section{References}

1 Boyle P, Leon ME: Epidemiology of colorectal cancer. Br Med Bull 2002;64:1-25.

2 Kemeny N: Management of liver metastases from colorectal cancer. Oncology 2006;20:1161-1176, 1179, (discussion) 1179-80, 1185-1186.

$\checkmark 3$ Pozzo C, Barone C, Kemeny NE: Advances in neoadjuvant therapy for colorectal cancer with liver metastases. Cancer Treat Rev 2008;34:293-301.

$\checkmark 4$ Blazeby JM, Fayers P, Conroy T, Sezer O, Ramage J, Rees M; European Organization for Research Treatment of Cancer (EORTC) Quality of Life Group: Validation of the European Organization for Research and Treatment of Cancer QLQLMC21 questionnaire for assessment of patient-reported outcomes during treatment of colorectal liver metastases. Br J Surg 2009;96:291-298.
5 Berretta M, Cappellani A, Di Benedetto F, Lleshi A, Talamini R, Canzonieri V, Zanet E, Bearz A, Nasti G, Lacchin T, Berretta S, Fisichella R, Balestreri L, Torresi A, Izzi I, Ortolani P, Tirelli U: Clinical presentation and outcome of colorectal cancer in HIV-positive patients: a clinical case-control study. Onkologie 2009;32:319-324.

6 Patel P, Hanson DL, Sullivan PS, Novak RM, Moorman AC, Tong TC, Holmberg SD, Brooks JT; Adult and Adolescent Spectrum of Disease Project and HIV Outpatient Study Investigators: Incidence of types of cancer among HIV-infected persons compared with the general population in the United States, 1992-2003. Ann Intern Med 2008;148:728-736.
7 De Gramont A, Figer A, Seymour M, Homerin M, Hmissi A, Cassidy J, Boni C, Cortes-Funes H, Cervantes A, Freyer G, Papamichael D, Le Bail N, Louvet C, Hendler D, de Braud F, Wilson C, Morvan F, Bonetti A: Leucovorin and fluorouracil with or without as first-line treatment in advanced colorectal cancer. J Clin Oncol 2000;18:2938-2947.

8 André T, Louvet C, Maindrault-Goebel F, Couteau C, Mabro M, Lotz JP, Gilles-Amar V, Krulik M, Carola E, Izrael V, de Gramont A: CPT-11 (Irinotecan) addition to bimonthly, high dose leucovorin and bolus and continuous-infusion 5-fluorouracil (FOLFIRI) for pretreated metastatic colorectal cancer. GERCOR. Eur J Can 1999;35:1343-1347. 